\title{
Enhancing Water Productivity for Agriculture and Adapting to Climate Change in Food Insecure Areas - Practical Experiences from Far and Mid West Nepal
}

\begin{abstract}
The Rural Village Water Resources Management Project Phase II (RVWRMP-II) works in some of the most remote, food insecure and water scarce areas of Nepal, where the impacts and effects of climate change are already visible. The farmers of the project region are dependent on rain-fed agriculture. Large parts of the project area (parts of Humla and Bajura Districts, for instance) depend on food aid.

In Phase II, specific attention is being paid to climate change adaptation, efficient use of water for agriculture, and food security and nutrition.

RVWRMP facilitates communities to design and implement Water Use Master Plans (WUMP). One of the objectives of a WUMP is to optimize the use of water for agriculture. Micro-irrigation, rain water harvesting, multi-use schemes, using drainage water from tap stands for home gardens and organic fertilizers are some of the ways to improve the food security in the communities. Water source protection, watershed conservation, soil protection and crop selection are key technical areas of interest to enable adaptation to the anticipated changes in climate.
\end{abstract}

Key words: Water Use Master Plan, Far and Mid Western Nepal, climate change adaptation, food security, Nepal

\section{Introduction}

The Rural Village Water Resources Management 1 Project Phase II (RVWRMP-II) is a bilateral development project implemented by the governments of Nepal and Finland. It works through District Development Committee (DDC) executed sub-projects in 53 remote Village Development Committees (VDCs) in 10 districts (Accham, Baitadi, Bajhang, Bajura, Dadeldhura, Dailekh, Darchula, Doti, Humla, and Kailali) in Far and Mid Western regions of Nepal. The working modality through Districts is fully decentralised and embedded into Local Self Governance System. The overall objective of RVWRMPII is institutionalised capacity at local and regional levels to sustain and continuously improve enhanced quality of life, better environmental conditions and increased opportunities in rural livelihoods in the project area. The project uses the principle of Integrated Water Resources Management to achieve the three result areas: Institutionalized community capacity in water supply and sanitation infrastructure and behaviour, improved and sustainable nutrition, food security and sustainable income at community level, and institutionalized capacity at district level to support communities in the above. The Water Use Master Plan (WUMP) at the VDC level sets the five year vision for each VDC, providing the priorities also for RVWRMP-supported individual schemes and activities.

This paper has two parts; the first part describes the challenging characteristics of the project area in terms of food security, water scarcity and vulnerability to climate change and other disasters. The second part describes the activities that are undertaken in these circumstances to enhance water productivity for agriculture and adapt to climate change.

\section{RVWRMP Project Area: Vulnerable, Dry, Remote and Food Insecure}

Although the project VDCs are biologically diverse and rich in natural resources, the area is more dry and prone to droughts than other parts of Nepal. While eastern Nepal receives approximately $2,500 \mathrm{~mm}$ of rainfall annually, far western Nepal receives 1,000 $\mathrm{mm}$ (GON 2008). The area is also highly prone to frequent natural disasters. The Mid and Far Western Regions are, by natural character, water scarce, fragile and prone to landslides. These natural conditions are further exacerbated by human activities, such as land use changes, deforestation, over-grazing, haphazard road cutting, and other forms of environmental exploitation and unplanned (infrastructure) activities. In addition, poor sanitation is causing annually serious cholera and other fatal diarrhoea outbreaks.

The area experiences different degrees of mostly seasonal food insecurity. As can be seen from Table 1, all the project districts are food deficit areas. The major crops in the area are paddy, maize, wheat, millet and barley. The most popular varieties of crops planted locally paddy rice, maize and wheat is rather sensitive to water scarcity, and therefore may be also badly affected by the impacts of climate change.

Productivity of the rain-fed subsistence farming is constrained by limited arable land, uncertain availability of water, inefficient water management, insufficient soil protection and enhancement, and limited crop selection. Other livelihoods strategies, such as livestock, migration to India for labour work, non-timber forest product (NTFP) collection, food aid, wage labour and employment opportunities by development projects are also not sustainably and continuously providing food security.

\section{Climate Change Impacts in the Project Area Increase Food Insecurity}

Changes in the regular weather pattern towards extreme weather conditions have already been observed. Over the past years the water flows have decreased from what they were during 2007 and 2008. During the winter of 2008/2009 the 'winter rains' were virtually absent in the project area, onset of 2009 monsoon was late, and atypical heavy rains in October 2009 resulted in landslides 


\begin{tabular}{|c|c|c|c|c|c|c|c|c|}
\hline \multirow{2}{*}{ District } & \multicolumn{5}{|c|}{ Edible Production (mt) } & \multirow{2}{*}{$\begin{array}{l}\text { Total Edible } \\
\text { Production } \\
\text { (mt) }\end{array}$} & \multirow{2}{*}{$\begin{array}{l}\text { Requirement } \\
\text { (mt) }\end{array}$} & \multirow{2}{*}{$\begin{array}{c}\text { Balance } \\
(+,-)\end{array}$} \\
\hline & Rice & Maize & Wheat & Millet & Barley & & & \\
\hline Humla & 449 & 83 & 67 & 1041 & 197 & 1836 & 9056 & -7220 \\
\hline Dailekh & 13469 & 28389 & 7289 & 2311 & 70 & 51527 & 53298 & -1771 \\
\hline Bajura & 2327 & 506 & 2429 & 1613 & 231 & 7106 & 24383 & -17277 \\
\hline Bajhang & 4798 & 1721 & 3769 & 1474 & 323 & 12085 & 37647 & -25562 \\
\hline Darchula & 3998 & 7167 & 4247 & 946 & 293 & 16651 & 27489 & -10838 \\
\hline Achham & 7361 & 3713 & 5539 & 2718 & 27 & 19358 & 54302 & -34944 \\
\hline Doti & 9746 & 358 & 20873 & 4344 & 49 & 35370 & 49663 & -14293 \\
\hline Baitadi & 5387 & 10778 & 4066 & 772 & 136 & 21139 & 55054 & -33915 \\
\hline Dadeldhura & 7049 & 1648 & 8867 & 292 & 33 & 17889 & 29968 & -12079 \\
\hline Totals (mt) & $2,185,936$ & $1,282,438$ & $1,248,333$ & 243,231 & 7,529 & $4,967,469$ & $5,297,444$ & $-157,899$ \\
\hline
\end{tabular}

Table 1. Total Edible Food Availability and Requirements in 2009/10 (Project Hilly Districts). (MOAC website)

\section{Climate Change Impacts in Humla and Northern Bajura}

In Humla and Northern Bajura climate change has had also positive impacts in terms of food security. Areas which used to be covered in snow for 6-7 months, now experience less snowfall and longer growing seasons. Vegetable crops like cauliflower and tomato can be grown for the first time. "I used to plant flowers around my house and cut and cover them for winter. The new buds would appear in May every year. Lately, the new buds have been appearing 2 months in advance" (Hojar Lama, Humla).

On the other hand, the receding snowline of the Himalayas is causing less water to be available for crops during spring time. For example in the 2009 WUMP of Maila VDC of Humla, it is reported that droughts, earthquakes and environmental degradation including deforestation have depleted water sources and decreased food security since around 2003 (Maila VDC 2009).

and loss of lives in the region. A small study conducted by RVWRMP in some weather stations of Far Western districts found that over a 20 year time span (1987 to 2006) winter rainfall has decreased and summer rainfall has increased significantly. Overall, monthly rainfall trend lines confirm that seasons are changing: rainfall appears to be decreasing during the winter season and increasing during the summer. Although the total annual rainfall average appears to have remained fairly similar in the region, rainfall intensity has increased. There seems to be consensus that storminess and rainfall intensity during monsoon may increase, resulting in more floods and landslides.

Poor or absent winter rains hamper farmers' chances to harvest the winter crop, which has been traditionally rain fed. This naturally impacts on the household's wellbeing and food security.

\section{Availability of Water Resources and Water Productivity}

There are three types of water resources that are being used for agriculture production. They are:

- Small rivers (permanent or seasonal),

- Traditional water collection ponds (Khaal and Nala), and

- Seasonal or permanent springs.

The traditional practices and systems such as earthen canals and collection ponds cause high levels of water loss during conveyance and application. Flooding water system is mostly inefficient for available water productivity in agriculture. Frequently, increasing temperature in the high hills with higher frequency of droughts has increased water scarcity in the project region.

The 'poly pipe revolution' (providing irrigation from local sources) has not addressed the water scarcity in the region. Deforestation, ecological disturbances and uncertain rainfalls have already decreased the number of water sources, and there are still disputes related to water and no proper operation and maintenance practices. Thus the pipeline water supplies are also insufficient to meet the requirement of the farmers for home gardening, nursery raising or livestock farming purposes. It means that effective use of water through poly pipes for agriculture requires more efficient and productive systems of water use.

The irrigation facilities developed by farmers are very limited and mostly owned by the elites. The only way to address this issue is to conserve the water resources and enhance water productivity in the field of agriculture, achieving greater production with improved technologies.

In the RVWRMP-II, specific attention is being paid to climate change adaptation, efficient use of water for agriculture and food security and nutrition with small-scale irrigation techniques, rain water harvesting, multi-use systems, water source protection, watershed conservation, soil protection and organic farming techniques with appropriate crop selection. 
Practical Activities of RVWRMP to Enhance Water Productivity for Agriculture and Adapt to Climate Change Integrated water resources management and planning: Water Use Master Plans

The Water Use Master Plan (WUMP) is the starting point of VDC level planning in RVWRMP project VDCs. The WUMP concept was first introduced by Helvetas Nepal as an inclusive, participatory, demand-driven planning process to map the available water resources on the one hand, and the users and water needs of the population on the other. It aims to ensure equitable, optimized water use in a VDC (Bhatta 2010). It follows the principle of integrated water resource management, taking a holistic, cross-sectoral view of water resources, and includes for example land use planning, agriculture and environmental management. During the WUMP development process, it is a non-negotiable principle that all community members, including women and disadvantaged groups, are given the opportunity to be heard.

During Phase I (2006-2010), RVWRMP facilitated communities to prepare 44 VDC-level WUMPs. The WUMPs covered water supply service improvement, including every household, while only partly covering other uses of water such as irrigation and hydro energy. Existing situation analysis and future planning was discussed and decided in Community Organisations at cluster level or in Sub-Committee at sub-watershed level and finalized in Water Resources Management Committees (WRMCs) at VDC level. WUMP preparation took place via close coordination and steering by the concerned VDCs to ensure commitment and ownership of the plan by the local authorities, political parties and the communities. The final WUMPs were approved by Village Councils and endorsed by District Councils in accordance with Government of Nepal planning steps. The WUMPs were not prepared for the RVWRMP project, but they are essentially owned by the respective VDCs. Only some of the schemes planned in the WUMPs will be implemented with the funds from the project.

The overall concept and its practical application were very useful for obtaining inclusive full coverage of all households, and it prevented lobbying for ad hoc schemes and constant interference with the priorities. However, especially in the beginning, it was observed that the WUMPs concentrated mostly on drinking water and did not pay full attention to the multipurpose potentials, conservation of water resources and sanitation. Systematic attention needs to be given to them. It was also learned that WUMP 'marketing' should start as early as possible and it should involve all other actors from the onset.

VDC level ownership for the WUMP is a must. The VDC and WRMC should understand their WUMP, know its priorities and how to market it (i.e., how to approach other projects, programmes and funding agencies for funds for schemes), as well as how to review it. However, the WUMPs as they were prepared in Phase I, turned out to be costly and complex, mainly because of the high amount of highly skilled human resources needed and the GIS applications. To make the WUMP concept more practical to VDCs even without much external funding, RVWRMP is contributing to developing the concept of a 'low-cost', or 'localight' (Helvetas term) WUMP at the national level.
During Phase II, the WUMPs will be reviewed to identify any changes, e.g., depletion of water sources. As of August 2011, most (on average 85\%) of the data for the WUMP review had been collected in nine out of ten districts. The aim is not to change the priority list as given in the original WUMPs but to ensure that especially sanitation and livelihoods related schemes as well as all possible Multiple Use Systems (MUS) were identified and included in the WUMP.

\section{Technical options to enhance water productivity: Irrigation, MUS, Rain Water Harvesting}

Since irrigation comes after water supply and sanitation in the WUMP priorities, in RVWRMP Phase I there were only 20 irrigation schemes, with a total command area of 389 ha and a population served of 10,00o. In addition there were nine Multiple Use Schemes (MUS), usually with micro-hydro, which also planned for irrigation. RVWRMP's menu of options includes non-conventional irrigation, usually with multiple-use water systems or as part of livelihoods improvement. Combinations of two or more technologies from the same source of water are preferred; e.g., drinking water supply and irrigation (any type), irrigation and micro-hydro, water supply, irrigation and micro-hydro, irrigation and improved water mill etc. There are also conventional (small) hill irrigation systems which are increasingly in demand, and after water supply, come high in WUMP priorities. Rehabilitation/repair of conventional irrigation schemes is also an option. These are sometimes done together with the micro-hydro projects where existing irrigation canals can be used to feed the micro-hydro as well. The project is not funding large conventional irrigation, and are discouraged. Rehabilitation/repair of such system can be funded from the project if identified in the WUMP.

In seriously water and food scarce areas, such as Humla, irrigation is an even higher priority than water supply: a villager in Humla requesting an irrigation rehabilitation scheme was quoted saying that "we can always carry water for drinking but we cannot carry it for the crops."

Drip irrigation is a method of watering precise amount of water drops right at the root zone. It maintains optimal soil moisture and enables healthy growth and minimum stress to the crops. During RVWRMP Phase I, the application of drip irrigation in the piloting villages was used especially for seasonal and off season vegetable production. Farmers became aware on reusing excess drainage from tap stands in the farm with drip irrigation. It also helped farmers to provide liquid fertilizers and micro nutrients to the vegetable plants through drips.

Most of the farmers have used four liner drip system which has 80 holes in total to irrigate 80 plants at once. By the end of Phase I, there were a total of 131 commercial farmers using and scaling up drip irrigation systems.

Sprinkler irrigation has gained popularity after its price has recently come down. In the project it is encouraged only in the villages where water discharge is relatively high, and for those who are involved in commercial level of cultivation and production. There are 101 farmers using sprinkler and growing vegetables and tree crops.

One demonstration of Drip or sprinkler (preferable drip) irrigation is mandatory in each farm based 
livelihoods event. As per the result indicator of Phase II, "70\% households of the project VDCs will have managed home gardens." It is therefore expected that 24,500 households will have mostly drip or sprinkler irrigation systems applied for their home gardens by the end of the Phase II.

Rain Water Harvesting (RWH) has a great potential to increase available water, both for drinking water and agricultural purposes. The majority of applications in RVWRMP have so far been mainly for drinking water purposes in the higher altitude belt where there are no other water sources. For small-scale irrigation purposes; some piloting has been done with simple earthen rain water harvesting ponds that allow the surface water to percolate slowly. Re-charging multipurpose seedlings were planted uphill. They have a potential to increase soil moisture at a low cost, decrease surface run-off and soil erosion, and improve drinking water sources downhill. As the benefits are long term and cannot be immediately felt, taking into account social aspects (ownership of land, who benefits) are crucial for avoiding conflict.

\section{Livelihoods, food security and nutrition: Organic farming techniques, appropriate crop selection and excess water drainage from tap stands to home gardens}

The crops grown in the project area are limited to a few varieties. Rice is the most popular cereal even in areas where it cannot be grown. This could be due to the fact that some of the areas, such as Humla and Bajura, are dependent on food aid in the form of rice, and the perception of rice as the "elite" staple food (Mahato 2011).

However, the project does not intensively focus on varieties of cereal crop production. The emphasis is on appropriate adaptation strategies, while carrying out sub-sector analyses for the most appropriate livelihoods techniques in specific areas. With awareness raising and capacity building at community level, the project encourages communities in:

- introduction of species with a shorter cropping period, in order to be able to complete the life cycle during rains,

- use of drought resistant winter crops such as wheat and millet,

- promotion of less water-sensitive crops- eg. tree crops, fodder grasses,

- land and water source protection activities decreasing grazing pressure, particularly in sensitive areas that are prone to erosion and landslides; increased stall feeding of livestock; planting of trees and grasses for soil stabilization,

- diversification rather than a single crop approach,

- use of renewable energy technologies to decrease pressure on forests and improve livelihoods, and

- improved integrated pest management, avoiding use of chemical pesticides and fertilizer where possible and use of animal waste.

Initiation of use and re-use of drainage water either from the tap or kitchen or hand washing for home gardens has promoted the efficient use of water. The project piloted agro-based livelihoods activities in eight VDCs in Phase I. Seasonal and off season vegetable crops were the main sub-sectors intervened. In Phase II, home gardens are meant to reach every household participating in the project activities.

The project has introduced different mixes of organic fertilizers, including farm yard manure, composting, liquid fertilizers from livestock urine and environmentally friendly insecticides and pesticides made from locally available forest species. The good results have motivated farmers to scale up these practices. After the project intervention, none of the farmers are using chemical fertilizers for their home garden production. The practice has saved money and increased soil nutrients.

\section{Increased Incomes from Organic Farming}

With the promotion of organic farming technologies, the average per household net additional income of 425 households that benefited from livelihoods pilots in the Phase I in Dailekh district increased from NRs. 3,700 in 2009 to NRs. 14,020 in July 2011.

\section{Adapting to climate change by environmental conservation measures}

The WUMPs prepared in Phase I proposed some environmental protection schemes, but in the Phase II WUMP review, it might turn out to be essential to include more activities related to soil and watershed protection. RVWRMP already promotes all three major dimensions of soil protection: Protection of the soil organic properties (through organic farming methods discussed earlier), protection against soil erosion (with bio-engineering schemes) and protection against soil contamination from plastics and other solid waste (garbage pits and overall cleanliness of villages are part of the sanitation awareness activities).

The concept of Water Safety Plan and its application to Mid and Far Western rural areas (for gravity flow drinking water systems) has been developed and forms part of the climate change adaptation practices of RVWRMP. A Water Safety Plan ensures the safety of drinking water through the use of a comprehensive risk assessment and risk management approach, that covers all steps in water supply from catchment to consumer (from water source to mouth) through a multiple barrier approach. Source protection is part of WSP. Source protection measures include both protection and improvement of the water quality of the source - protection from source contamination and source yield protection via improvement of the catchment area and watershed management.

\section{Conclusion}

Far and Mid Western Nepal is a remote area that is already facing the early signs of climate change and more serious impacts can be expected in the future. Climate change impacts are most of all unpredictable: water might be either too much or too little and at the wrong times. RVWRMP is using an integrated approach to water resources management, giving consideration to climate change adaptation, the efficient use of water for agriculture, 
food security and nutrition. The lessons learned from the different technical and environmental options will be used to reduce vulnerability and improve livelihoods.

\section{Acknowledgements}

Janak Bhattarai (Water Resource Officer), Raju Tirwa (Water Resource Advisor), Sanna-Leena Rautanen (Team Leader of RVWRMP) and Pamela White (Home Office Coordinator of RVWRMP) have also contributed to the contents of this paper.

Kaisa Seppänen is the Field Specialist of RVWRMPII. She holds a BSc. Degree in Forestry and an MA in Environment and Development, and has a special interest in livelihoods and climate change issues. She has previously worked with small scale renewable energy technologies and forest communities in Kenya, and with climate change issues in Indonesia.

Corresponding address:kaisa.rvwrmp@gmail.com

Chakra Bahadur Chand is the Sustainable Livelihoods Specialist of RVWRMP. He has 17 years of experience in planning, designing and implementing different income-generation and livelihoods interventions. Before RVWRMP, he has worked with Helvetas Nepal and the Rural Development Bank on livelihoods and microfinance issues.

\section{References}

Bhatta, MK., 2010, 'Water Use Master Plan (WUMP) and climate change', a paper presented in the Face-to-Face Workshop on Natural Resources Management and
Climate Change held in Mekelle, Ethiopia,m October 24-31, 2010.

GON, 2008, National Capacity Self-Assessment for Global Environment Management, Government of Nepal/ Ministry of Environment, Science and Technology; UNDP; and Global Environment Facility.

Mahato, R., 2011, 'Feeding the Karnali: The Karnali can feed itself if its unique food resources are harnessed', Nepali Times, No.549 (April 15, 2011), p.15. URL: www. nepalitimes.com/issue/2011/04/15/Nation/18119.

Maila VDC, 2009, Water Use Master Plan (Main Report in English), Maila Village Development Committee, Humla District, Nepal: Water Resources Management Committee.

MOAC web site. URL: www.moac.gov.np/content.php?id=10. RVWRMP-II(a), 2011 (May), Final Project Document, Rural Village Water Resources Management Project, Phase II, in Far and Midwestern Regions of Nepal, Kathmandu: Ministry of Local Development/ Department of Local Infrastructure and Agricultural Roads, Kathmandu. URL: rvwrmp.org.np/downloads/. RVWRMP-II(b), 2011 (May), Inception Report. Rural Village Water Resources Management Project, Phase II, in Far and Midwestern Regions of Nepal, Kathmandu: Ministry of Local Development/ Department of Local Infrastructure and Agricultural Roads. URL: rvwrmp.org.np/downloads/.

RVWRMP-II, 2011 (September), Annual Progress Report (final draft to be presented to the Supervisory Board). Rural Village Water Resources Management Project, Phase II, in Far and Midwestern Regions of Nepal, Kathmandu: Ministry of Local Development/ Department of Local Infrastructure and Agricultural Roads. URL: rvwrmp.org.np/downloads/.

Continued on Page 53...

\section{References}

Bhandari, D.N., 2008, 'Living with uncertainty: Climate change and disasters-Melting glaciers, pp.16-20 in NGO Group Bulletin on Climate Change, Issue 2: Local Initiatives for Biodiversity Research and Development, pp.16-20.

Dahal H., D.M. Pokhrel and B. Pandey, 2011, National Adaptation Program of Actions to Climate Change: Food Security and Agro-Biodiversity Management in Nepal. URL: www.moac.gov.np/bidesh/DrDahal_ Presentationpptrecent2.pdf.

FAO, 2003, Unlocking the Water Potential for Agriculture. Rome: UN Food and Agriculture Organization. URL: fao.org/DOCREP/o06/Y4525E/Y4525E0o.HTML.

Ghimire R. and P. Bista, 2009, 'Conservation agriculture rally-rounds adaptation to climate change', pp.16-20 in Group Bulletin on Climate Change, Issue 3: Scaling up Community Based Adaptation in Nepal, Local Initiative for Biodiversity Research and Development..
Ghimire, R., 2008, 'Increasing resilience of community on climate change through application of sloping agriculture land technology and eco-friendly agriculture in Jugedi Khola watershed, Nepal', Geographical Forum, Journal of Geographical Studies and Environment Protection Research 7 (7):208-215.

McGarry, D., 2009, 'Mitigating climate change and better ensuring agriculture's adaptation for impending climate change through conservation agriculture', pp.362-372 in Proceedings of the Fourth World Congress on Conservation Agriculture, 4-7 February, 2009, New Delhi.

Reij, C. and A. Waters-Bayer (eds.), 2001, Farmer Innovation in Africa: A Source of Inspiration for Agricultural Development, London: Earthscan.

Shrestha, A.B., C.P. Wake P., A. Mayewski and J.E. Dibbl, 1999, 'Maximum temperature trends in the Himalaya and its vicinity: An analysis based on temperature records from Nepal for the period 1971-94, Journal of Climate 12:2775-2787. 